\title{
Analysis of Genetic Diversity Amongst Fusarium spp. Associated with Root Rot of Apple
}

\author{
Mohit Sharma, Apoorva Kapatia and Saurabh Kulshrestha*
}

Faculty of Applied Sciences and Biotechnology, Shoolini University of Biotechnology and Management Sciences, Bajhol, Solan, Himachal Pradesh, India.

\author{
http://dx.doi.org/10.13005/bbra/2055
}

(Received: 09 January 2016; accepted: 20 February 2016)

\begin{abstract}
The Genus Fusarium is associated with crop diseases of horticultural and agricultural commodities and is considered to be a destructive pathogen. Genetic diversity among ten different isolates of Fusarium species isolated from apple rhizosphere from different locations of Himachal Pradesh was analysed using Random Amplified Polymorphic DNA (RAPD-PCR). Molecular characterization using ITS sequencing revealed that out of 10 isolates of Fusarium, three belongs to $F$. oxysporum, two belongs to $F$. solani, one belongs to $F$. equiseti and four were Fusarium species. Seven random primers were used for their genetic characterization using RAPD analysis. The dendrogram obtained from the UPGMA study characterized ten isolates into one main cluster and nine independent branches on the basis of similarity value 0.65 .
\end{abstract}

Key words: Fusarium, Apple, RAPD, ITS, TEF.

Fusarium is one of the devastating phytopathogenic fungi belongs to Division Ascomycota, Class: Sordariomycetes, Order Hypocreales, Family: Nectriaceae. This filamentous fungi, can smite any crop since having a broad host range including rice, wheat, horticultural crops, ornamentals and in almost all agricultural commodities (Supyani and Widadi, 2015). Species of Fusarium serving as pathogens to many diseases in crops such as vascular wilt, root rot, corm rot, damping-off, yellows, and others. Mostly Fusarium species are regarded as soilborne fungi because of their abundance in soil and their frequent association with plant roots, as parasites and saprophytes. However, many have active or passive means of dispersal in the

\footnotetext{
* To whom all correspondence should be addressed. Tel:- +91-1792-308000 Ex. 2022, +91-9459241393 Fax:- +91-1792-308000

E mail:- saurabh_kul2000@yahoo.co.in, sourabhkulshreshtha@shooliniuniversity.com
}

atmosphere and are common in colonizers of aerial plant parts, where they may result in diseases of substantial economic importance. Fusarium rot on apples by Fusarium species (Riad and Zeiden, 2015), Sugarcane wilt by Fusarium sacchari (Lin et al., 2014), Pokkah Boeng in sugarcane by Fusarium moniliforme (Vishwakarma et al., 2013), Bakanae in rice by Fusarium fujikuroi (Jain et al., 2014), Oil palm wilt by Fusarium oxysporum f.sp. elaidis (Rusli et al., 2015), Panama disease by Fusarium oxysporum f.sp. cubensis (Zhang et al., 2013), are some important diseases caused by Fusarium spp.

Fusarium taxonomy is very complex and over the last 100 years has persistently been rationalized. The traditional diagnostic method based only on morphological characteristics observed on selective media under specific incubation conditions for detection and identification of Fusarium species. Considerable expertise is required for morphological identification while differentiating closely related 
species of Fusarium as their morphological features may overlap. Molecular biology has brought many powerful tools to fungal taxonomists including method for identification of isolates, means to illuminate the relationships among fungal species. To define fungal populations at species, intraspecific, race and strain levels, RAPD assays have been extensively used (Miller, 1996; Ingle et al., 2009) and for detecting genetic variability RAPDPCR technique is also used (Edwards et al., 2002; Sabir, 2006).

The present study was aimed to estimate genetic relatedness among the Fusarium isolates, isolated from apple rhizosphere from different locations of Himachal Pradesh using RAPD markers.

\section{MATERIAL AND METHOD}

\section{DNA isolation}

Thirteen isolates of Fusarium species collected from different locations of Shimla, Kullu and Mandi were cultured on potato dextrose agar (PDA) plates containing $1 \mu \mathrm{g} / \mathrm{ml}$ streptomycin, incubated at $27^{\circ} \mathrm{C}$ for $3-5$ days. The mycelia grown were harvested and total DNA was extracted using protocol described by Sambrook et al., 1989. Crushing of harvested mycelia was done in 1-2 ml of extraction buffer (100mM Tris HCl, 50mM EDTA, $500 \mathrm{mM} \mathrm{NaCl}, 0.01 \% \beta$-mercaptoethanol). $130 \mu \mathrm{l}$ of $10 \%$ sodium dodecyl sulphate (SDS) was added to the mixture per $\mathrm{ml}$ of extraction buffer and incubated at $65^{\circ} \mathrm{C}$ for 15 minutes. The sample was centrifuged at $8,000 \mathrm{rpm}$ for $10 \mathrm{~min}$. To the supernatant, equal volume of phenol/chloroform (1:1) was added, mixed thoroughly and centrifuged at 10,000 rpm for $10 \mathrm{~min}$. Aqueous phase containing nucleic acid was collected and 2.5 volume of absolute ethanol was added to precipitate the nucleic acid. Sample was centrifuged at 12,000 rpm for $20 \mathrm{~min}$ to pellet down the precipitates. The pellet was then washed with $70 \%$ ethanol, air dried and resuspended in $50 \mu \mathrm{l}$ of $10 \mathrm{X}$ TE buffer (10mM Tris $\mathrm{HCl}, 50 \mathrm{mM}$ EDTA). Bands corresponding to genomic DNA were observed by performing electrophoresis in $1 \%$ agarose gel.

\section{Molecular characterization of fungal isolates by PCR}

The ITS region and Transcription eleongation of the isolates was amplified with primers ITS-Fu-F (5'CAACTCCCAAACCCCTGTGA-3'), ITS-Fu-R (5'GCGACGATTACCAGTAACGA-3'), TEF-Fu3F (5'GGTATCGACAAGCGAACCAT-3'), TEF-Fu3R (5'TAGTAGCGGGGAGTCTCGAA-3'), ITS-Fu1F (5'ACAACTCATAACCCTGTGAACAT-3'), ITSFu1R(5'-CAGAAGTTGGGTGTTTTACGG-3')(Arif et al., 2012). PCR was conducted in $20 \mu \mathrm{l}$ mixture containing $1 \mu \mathrm{l}$ DNA ( 50ng), 1.5mM dNTP mix, 10 pmole each of upstream and downstream primers and 0.045 units of Taq polymerase (Banglore Genei) with $1 \mathrm{X}$ buffer. Cycling conditions for PCR were: initial denaturation at $95^{\circ} \mathrm{C}$ for $3 \mathrm{~min}, 35$ cycles at $95^{\circ} \mathrm{C}$ for $1 \mathrm{~min}, 46^{\circ} \mathrm{C}$ for $1 \mathrm{~min}, 72^{\circ} \mathrm{C}$ for $1 \mathrm{~min}$, and a final elongation at $72^{\circ} \mathrm{C}$ for $10 \mathrm{~min}$. The PCR product was analyzed by agarose gel electrophoresis.

PCR Purification of Amplified DNA Product

PCR amplified DNA products were purified from gel using gel purification kit (DNA gel/PCR purification miniprep kit, XcelGen) as per the instructions provided in the instruction manual.

\section{Sequencing and Sequence analysis}

The eluted DNA was sent to Xcelris ${ }^{\mathrm{TM}}$ lab Pvt Ltd (Ahmedabad) for sequencing. Sequence data obtained was analysed using BLAST software. Sequences obtained were submitted to European Nucleotide Archive and accession numbers were obtained.

\section{Diversity Analyses of Isolated Fungal Strains} Using Random Amplified Polymorphic DNA (RAPD)

Isolated DNA (Sambrook et al., 1989) from Fusarium species was used to study the genetic variation using RAPD. The standard RAPD reaction was set up by using standard RAPD primers. Seven RAPD primers [TC-01 (5'GGAGTACTGG-3'), TC-03(5'-GAGTCTCAGG-3'), OPA-01 (5'-CAGGCCCTTC-3'), OPA-14 (5'TCTGTGCTGG-3'), OPA-17 (5'-GACCGCTTGT-3'), OPG-5 (5'-CTGAGACGGA-3'), and OPC-13 (5'AAGCCTCGTC-3')] were used in this study. PCR was conducted in $25 \mu \mathrm{l}$ reaction mixture containing $1 \mu \mathrm{l}$ DNA ( 50ng), $2 \mathrm{mM}$ dNTP mix, $2 \mu \mathrm{l}$ of random primers and 0.045 units of Taq polymerase (Banglore Genei) with $1 \mathrm{X}$ buffer. Cycling conditions for PCR were: initial denaturation at $94^{\circ} \mathrm{C}$ for $5 \mathrm{~min}$, 40 cycles at $94^{\circ} \mathrm{C}$ for $30 \mathrm{sec}, 36^{\circ} \mathrm{C}$ for $1 \mathrm{~min}, 72^{\circ} \mathrm{C}$ for $1 \mathrm{~min}$, and a final elongation at $72^{\circ} \mathrm{C}$ for $7 \mathrm{~min}$. The PCR product was analyzed by agarose gel 
electrophoresis.

\section{RAPD product scoring and data analysis}

Data was compiled as binary 0-1 matrix, (1) represented the presence of a band and (0) the absence of a band at a particular position. All RAPD bands were considered in statistical analysis. Dendrogram was produced from the distance matrix by Unweighted Pair-Grouped Method by Arithmetic average, contained in the software package NTsys 2.2 version.

\section{RESULTSAND DISCUSSION}

\section{DNA isolation}

To study the diversity among the Fusarium species, samples were collected from apple rhizosphere in orchards of Himachal Pradesh, India.

All the strains have been purified by growing the single spores on PDA plate and DNA of thirteen isolates was extracted manually using phenol/chloroform method in a good quantity.

\section{Molecular Characterization}

Isolated Fusarium strains were confirmed by molecular characteristics i.e. by PCR amplification of ITS region and transcription elongation factor - alpha, recommended as a universal DNA barcode marker for fungi (Schoch et al., 2012). For a single-locus identification in Fusarium, TEF markers has become a choice (Geiser et al., 2004). Three primers sets: ITS FuFFuR, ITS Fu1F-Fu1R corresponding to ITS region and TEF Fu3F-Fu3R corresponding to transcription elongation factor - alpha region showed amplification at $400 \mathrm{bp}$ which confirmed that ten of the thirteen isolates under study were Fusarium (Table 1). Arif et al., (2012) designed the primers for ITS, TEF for rapid detection of genus Fusarium and $F$. solani. The primers had shown accurate identification and discrimination of genus Fusarium and F. solani, which have number of applications in screening of infected plants, disease diagnosing and breeding programs. Purified PCR product of primers ITS FuF-FuR and TEF Fu3FFu3R of ten fungal isolates were sent to Xcelris ${ }^{\mathrm{TM}}$ lab Pvt. Ltd. for sequencing. Sequence data obtained was analysed using BLAST software and found that out of ten Fusarium isolates three isolates (isolate 4, isolate 5 and isolate 12) belongs to $F$. oxysporum, two isolates (isolate 2 and isolate 13) belongs to $F$. solani , one isolate (isolate 9 ) to be $F$. equiseti and other four belongs to strains of Fusarium species. The sequences were assigned accession numbers by submitting to European

Table 1. PCR amplification of fungal isolates with ITS and TEF primers

\begin{tabular}{lllllllllllllll}
\hline Primer name & \multicolumn{110}{c}{ Name of isolates } \\
\cline { 2 - 14 } & 1 & 2 & 3 & 4 & 5 & 6 & 7 & 8 & 9 & 10 & 11 & 12 & 13 \\
\hline ITS FuF-FuR & + & + & - & + & + & - & + & + & + & + & - & + & + \\
ITS Fu1F-Fu1R & + & + & - & + & + & - & + & + & + & + & - & + & + \\
TEF Fu3F-Fu3R & + & + & - & + & + & - & + & + & + & + & - & + & + \\
\hline
\end{tabular}

(+ indicates amplification, - indicates non amplification)

Table 2. Sequence of primers, number and size of fragments of Fusarium species amplified by RAPD primers

\begin{tabular}{lllcccc}
\hline $\begin{array}{l}\text { Sr } \\
\text { No }\end{array}$ & Primers & Sequences 5'-3' & $\begin{array}{c}\text { Amplified } \\
\text { fragments }\end{array}$ & $\begin{array}{c}\text { Polymorphic } \\
\text { fragments }\end{array}$ & $\begin{array}{c}\text { Maximum } \\
\text { band size (bp) }\end{array}$ & $\begin{array}{c}\text { Minimum } \\
\text { band size (bp) }\end{array}$ \\
\hline 1 & OPA 1 & GGAGTACTGG & 28 & 7 & 1750 & 450 \\
2 & OPA 14 & GAGTCTCAGG & 20 & 5 & 1000 & 250 \\
3 & OPA 17 & CAGGCCCTTC & 15 & 6 & 910 & 400 \\
4 & TC 1 & TCTGTGCTGG & 21 & 5 & 1700 & 400 \\
5 & TC 3 & GACCGCTTGT & 17 & 3 & 1250 & 480 \\
6 & OPG 5 & CTGAGACGGA & 43 & 6 & 1820 & 460 \\
7 & OPC 13 & AAGCCTCGTC & 41 & 6 & 2960 & 400 \\
\hline
\end{tabular}




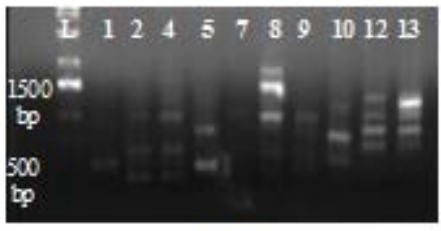

OPA 1

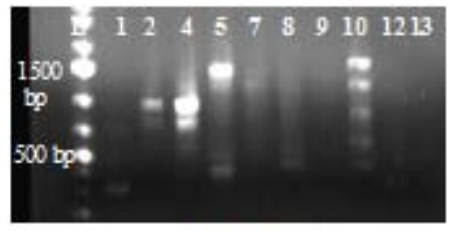

OPA 14

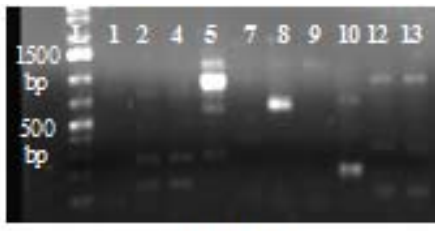

OPA 17

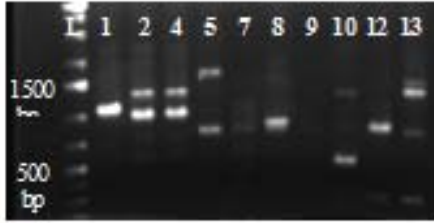

TC 1

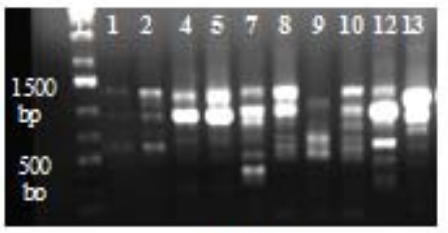

OPS 5

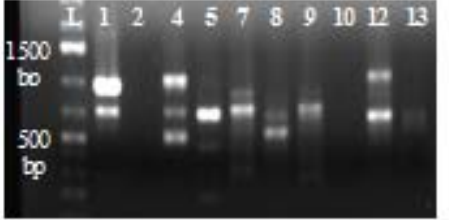

TC 3

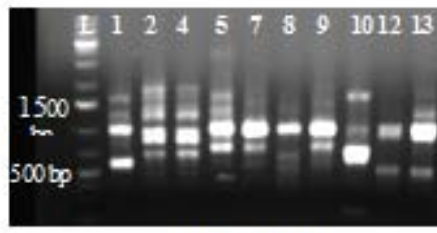

OPC 13

Fig. 1. RAPD banding patterns of ten Fusarium isolates using seven selected random primers on 1\% agarose gel. lane L: ladder $1 \mathrm{~kb}$ plus, lane 1-13 ten isolates of Fusarium species, respectively

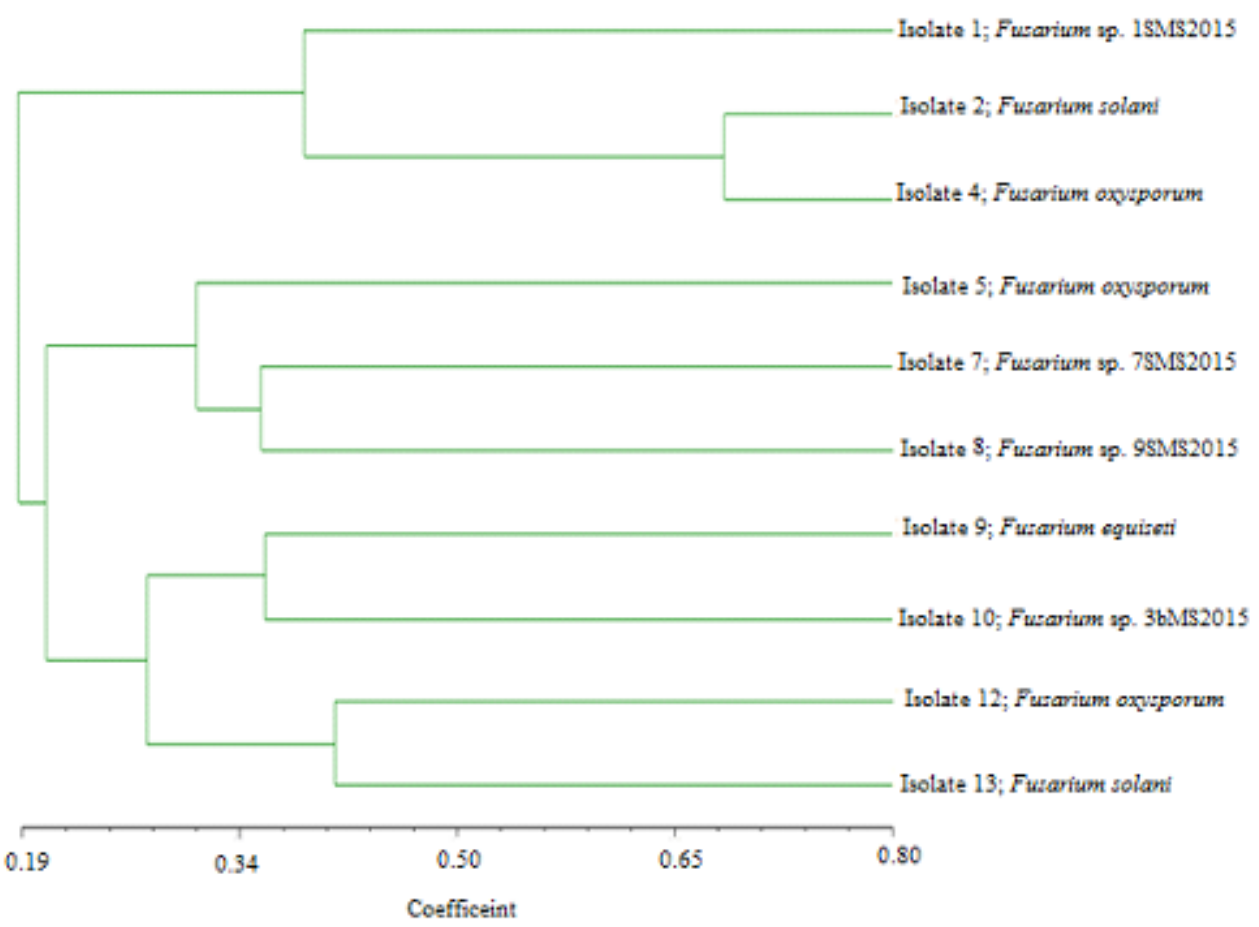

Fig. 2. Dendrogram of Fusarium species derived from RAPD fingerprints generated by using seven different primers produced from the distance matrix by Unweighted Pair-Grouped Method by Arithmetic average, contained in the software package NTsys 2.2 version 
Nucleotide Archive the entries permanently available from the ENA browser at http:// www.ebi.ac.uk/ena/data/view/LN886527LN886536.

\section{RAPD Analysis}

Isolated DNA from ten isolates of

Fusarium species was used to study the genetic variation using RAPD. RAPD, a method widely used to characterize isolates, indicated a high level of genetic variability among isolates of Fungi (Bahmani et al., 2012). The standard RAPD reaction was set up by using standard RAPD primers. Seven random primers viz; OPA-01, OPA-14, OPA-17, TC01, TC-03, OPG-5 and OPC-13, which generated reproducible RAPD patterns were used for a comparative analysis of ten selected fungal isolates (Figure 1). For RAPD, a total of 28, 20, 15, 21, 17, 43 and 41 bands were scored by using specific primers OPA-01, OPA-14, OPA-17, TC-01, TC-03, OPG-5 and OPC-13 respectively (Table 2). Out of total amplified fragments obtained from each primer 7, 5, 6, 5, 3, 6 and 6 polymorphic fragments were shown by OPA-01, OPA-14, OPA-17, TC-01, TC-03, OPG-5 and OPC-13 respectively. The number and size of amplified products resulted from random primers were varied between $15-43$ and $250-2960$ bp respectively. The dendrogram obtained from the UPGMA study characterized ten isolates into one main cluster and nine independent branches on the basis of similarity and on similarity value 0.65 (Figure 2). The independent branches consist of isolate 1, 5, 7, 8, 9, 10,12 and 13. However, isolate 2 and 4 were found to be similar with each other on the similarity value nearly 0.70 . AlTuwaijri, (2015) in Saudi Arabia characterized eight isolates of $F$. oxysporum $f$. sp. cucumerinum, the causal agent of Fusarium wilt of cucumber. Their isolates were subdivided into two sub clusters, one of them included isolate Fus 6 only and second include the rest of seven Fusarium isolates with different similarity values. Bonde et al., (2014) studied genetic variations in ten isolates of $F$. equiseti isolated from different fruits and vegetables by RAPD. Hierarchical clustering distinguished the isolates into three groups on the basis of similarity and $0.02-0.15$ was the range of similarity coefficient for all isolates. Hafizi et al., (2013) in Malayasia studied morphological and molecular characterization of $F$. solani and $F$. oxysporum associated with crown disease of oil palm. Cluster analysis revealed that the isolates in both Fusarium species were divided into two main clusters with the percentage of similarity from $87 \%$ $100 \%$ for F. solani and $89 \%-100 \%$ for F. oxysporum and isolates were highly variable. Gupta, (2012) reported PCR-RAPD profiling of Fusarium species; F.oxysporum $f$. sp. psidii and $F$. solani causing Guava wilt disease in India. Cluster analysis clearly separated the isolates of F.oxysporum and F. solani into three and two clusters respectively, showing a higher degree of similarity. Gupta et al., (2009) studied genetic polymorphism in isolates of $F$. solani collected from different places in India on the basis of Carboxylesterases isozyme pattern and DNA polymorphism. Results revealed polymorphism within the isolates and established DNA fingerprints useful for genetic characterization.

Our results suggest the existence of significant genetic variation among Fusarium species isolated from apple rhizosphere. Fusarium species contribute to many diseases such as root rot, vascular wilt and fruit rot in apple. So to combat these problems, the present study of genetic diversity of Fusarium species will be useful.

\section{ACKNOWLEDGEMENTS}

The authors would like to thank Prof. P. K. Khosla, Hon’ble Vice-Chancellor, Shoolini University of Biotechnology and Management Sciences, Solan and Foundation for Life Sciences and Business Management (FLSBM), Solan for providing financial support and necessary facilities.

\section{REFERENCES}

1. Al- Tuwaijiri, M. M. Y. Studies on Fusarium wilt disease of cucumber. Journal of Applied Pharmaceutical Science, 2015; 5(2): 110-119.

2. Arif, M., Chawla, S., Zaidi, N.W., Rayar, J. K., Variar, M. and Singh, U. S. Development of specific primers for genus Fusarium and F. solani using rDNA subunit and transcription elongation factor (TEF-1á) gene. Afr J Biotechnol., 2012; 11(2): 444-447.

3. Bahmani, Z., Nejad, R. F., Nourollahi, K., Fayazi, F. and Mahinpo V. Investigation of Fusarium verticilliodes on the basis of RAPD analysis and vegetative compatibility in Iran. $J$ 
plant Pathol Microb., 2012; 3: 147.

4. Bonde, S. R., Gade, A. K. and Rai, M. K. Genetic variations among ten isolates of $F$. equiseti (Corda) Saccardo isolated from fruits and vegetables. Austin J Biotechnol Bioeng., 2014; l(5): 5 .

5. Edwards, S. G., Callaghan, J. and Dobson A. W. PCR-based detection and quantification of mycotoxigenic Fungi. Mycol Res., 2002; 106:1005-1025.

6. Geiser, D. M., Jimenez-Gasco, M. d. M., Kang, S., Makalowska, I., Veeraraghavan, N., Ward, T. J., Zhang, N., Kulda, G. A. and Donnel, K. FUSARIUM-ID v 1.0: A DNA sequence database for identifying Fusarium. Eur J Plant Pathol., 2004; 110: 473-479.

7. Gupta, V. K. PCR-RAPD profiling of Fusarium spp. causing guava wilt disease in India. $J$ Environ Sci Health B: Pesticides Food Contaminants and Agricultural wastes, 2012; 47(4): 315-325.

8. Gupta, V. K., Mishra, A. K., Gaur, R., Pandey, R. and Chauhan, U. K. Studies of genetic polymorphism in the isolates of Fusarium solani. Austr J Crop Sci., 2009; 3:101-106.

9. Hafizi, R., Salleh, B. and Latiffah, Z. Morphological and molecular characterization of Fusarium solani and F. oxysporum associated with crown disease of Oil Palm. Braz J Microbiol., 2013; 44(3): 959-968.

10. Ingle, A. P., Karwa, A., Rai, M. K. and Gherbawy, Y. Fusarium: Molecular detection, mycotoxins and biocontrol. In: Gherbawy Y., Mach R., Rai M. (Eds.) Current Advance in Molecular Mycology. Science publishers Inc., Enfield, New Hampshire 2009.

11. Jain. S. K., Khilari, K., Ali, M., and Singh, R. Response of Fusarium monoliforme- the causal organism of Bakanae Disease of rice against different fungicides. The Bioscan, 2014; 9(1): 413-416.
12. Lin, Z., Xu, S., Que, Y., Wang, J. and Comstock, J. C. Species- specific Detection and Identification of Fusarium species complex, the causal agent of Sugarcane Pokkah Boeng in China. PLoS one, 2014; 9(8): e 104195.

13. Miller, S. Detecting propagules of plant pathogenic fungi. Adv Bot Res., 1996; 23:73102.

14. Riad, E. M. R. S. and Zeidan, E. S. H. First record of core rot on Apple fruit CV. Anna 106 local cultivar in Egypt. Journal of Agricultural Technology, 2015; 11(6): 1371-1380.

15. Rusli, M. H., Idris, A. S., and Cooper, R. M. Evaluation of Malaysian oil palm progenies for susceptibility, resistance or tolerance of Fusarium oxysporum f.sp. elaedis and defense related gene expression in roots. Plant Pathol., 2015; 64: 638-647.

16. Sabir, S. M. Genotypic identification for some Fusarium sambucinum strains isolated from Wheat in Upper Egypt. World J Agri Sci., 2006; 2(1): 6-10.

17. Schoch, C. L., Seifert, K. A., Huhndorf, S., Robert, V., Spouge, J. L., Levesque, C. A., Chen, W. and Fungal Barcoding Consortium. Nuclear ribosomal internal transcribed spacer (ITS) region as a universal DNA barcode marker for Fungi. Proc Natl Acad Sci U S A., 2012; 109(16): 6241-6246.

18. Supyani and Widadi, S. Hypovirulent isolates of Fusarium collected from chili crops in Boyolali Regency, Central Java, Indonesia. AGRIVITA, 2015; 37(1): 67-74.

19. Vishwakarma, S. K., Kumar, P., Nigam, A., Singh, A. and Kumar, A. Pokkah Boeng: An emerging disease of sugarcane. J Plant Pathol Microb., 2013; 4: 170.

20. Zhang, H., Mallik, A. and Zeng, R. S. Control of panama disease of banana by rotating and intercroping with Chinese chive (Allium Tyberosum Rottler) role of plant volatiles. $J$ Chem Ecol., 2013; 39: 243-252. 